\title{
Correlation of serum delta-like ligand-4 level with the severity of diabetic retinopathy
}

\author{
Yan Zhu ${ }^{1 \dagger}$, Jingcheng $\mathrm{Hu}^{1 \dagger}$, Xuan $\mathrm{Du}^{1}$, Qionglei Fang ${ }^{1}$, Yingyi Zhou ${ }^{1 *}$ and Ke Chen ${ }^{1,2^{*}}$
}

\begin{abstract}
Background: Diabetic retinopathy (DR) is one of the most serious microvascular complications of type 2 diabetes mellitus (T2DM). Delta-like ligand-4 (DLL4) maintains the normal physiological microenvironment of the retina. However, the relationship between the level of DLL4 and the severity of DR remains unclear.

Methods: We retrospectively analyzed serum DLL4 levels and other laboratory and clinical data in 94 T2DM patients (35 patients without DR [NDR], 32 with non-proliferative DR [NPDR], 27 with proliferative DR [PDR]), and 30 healthy controls.

Results: The serum DLL4 level was significantly greater in the NDR group (43.38 $\pm 16.23 \mathrm{pg} / \mathrm{mL})$, NPDR group $(56.57 \pm 25.89 \mathrm{pg} / \mathrm{mL})$, and PDR group $(74.97 \pm 25.28 \mathrm{pg} / \mathrm{mL})$ than in the healthy controls $(29.9 \pm 8.92 \mathrm{pg} / \mathrm{mL}$; all $p<$ 0.05). Among T2DM patients, the level of DLL4 increased as the severity of DR increased $(p<0.05)$. Logistic

regression analysis demonstrated that DR was positively associated with DLL4, glycosylated hemoglobin (HbA1c), fasting blood glucose (FBG), and duration of T2DM (all $p<0.05$ ). Consistently, receiver operating characteristic (ROC) curve analysis also indicated that DLL4 was a potential candidate biomarker for identifying the severity of DR.

Conclusions: T2DM patients, especially those with DR, have increased serum levels of DLL4. DLL4 may be used as a biomarker and an independent risk factor for DR, and targeting DLL4 may be a potential therapy in patients with DR.
\end{abstract}

Keywords: Type 2 diabetes mellitus, Diabetic retinopathy, Delta-like ligand-4, Independent risk factor

\section{Background}

Diabetes mellitus (DM) is a metabolic disease that has multiple etiologies and is characterized by hyperglycemia and the abnormal metabolism of glucose, fat, and protein due to insufficient insulin secretion and/or insulin resistance [1, 2]. According to the 2017 International Diabetes Federation (IDF) Global Diabetes Survey, about 425 million people worldwide suffer from DM, and

\footnotetext{
*Correspondence: Renee1987@qq.com; chenkework_1987@163.com Yingyi Zhou and Ke Chen are regarded as the co-corresponding authors. ${ }^{\dagger}$ Yan Zhu and Jingcheng Hu contributed equally to this work.

'Department of Endocrinology, The First Affiliated Hospital of Soochow University, No.188 Shizi Road, Suzhou, China

Full list of author information is available at the end of the article
}

114 million adults (20-79 years-old) in China have DM, accounting for about $10 \%$ of all adults in China [3]. Thus, China has more adults with DM than any other country.

Diabetic retinopathy (DR), one of the most serious microvascular complications of DM, is the main cause of blindness in working-age individuals [4], and is present in about one-third of DM patients. In China, the risk of blindness in DM patients is about 25-times higher than in non-DM patients, and the severity and risk of DR increases as DM progresses [5] During the early stages of DR, patients are usually asymptomatic. About $25 \%$ of patients already have early-stage DR at the initial

C C The Author(s). 2021 Open Access This article is licensed under a Creative Commons Attribution 4.0 International License, which permits use, sharing, adaptation, distribution and reproduction in any medium or format, as long as you give appropriate credit to the original author(s) and the source, provide a link to the Creative Commons licence, and indicate if changes were made. The images or other third party material in this article are included in the article's Creative Commons licence, unless indicated otherwise in a credit line to the material. If material is not included in the article's Creative Commons licence and your intended use is not permitted by statutory regulation or exceeds the permitted use, you will need to obtain permission directly from the copyright holder. To view a copy of this licence, visit http://creativecommons.org/licenses/by/4.0/ The Creative Commons Public Domain Dedication waiver (http://creativecommons.org/publicdomain/zero/1.0/) applies to the data made available in this article, unless otherwise stated in a credit line to the data. 
diagnosis of $\mathrm{DM}$, and $60 \%$ of patients who had type 2 DM (T2DM) for more than 20 years have fundus lesions of different severities [6]. Without prompt treatment, DR can seriously impair vision and eventually lead to blindness. Therefore, the early prevention and diagnosis and the timely and effective treatment of DR are very important for these patients.

Delta-like ligand 4 (DLL4), which is a ligand of the notch receptor, is a type I transmembrane protein composed of 685 amino acids whose gene is located on chromosome 15Q14 [7]. Notch maintains the normal physiological microenvironment of the retina and participates in the generation of retinal neovascularization under hypoxia. DLL4 is one of several ligands of notch proteins, its expression is greater in the presence of physiological and pathological neovascularization, and it plays an important regulatory role in retinal angiogenesis [8]. DLL4-mediated notch signaling is essential for islet function and insulin secretion in humans, but the relationship between DLL4 and DR remains incompletely understood.

In the present study, we examined the association of the serum level of DLL4 with the occurrence and progression of DR, and assessed the possible use of serum DLL4 as a risk factor for DR and a potential target for treatment of DR. Thus, we compared the clinical characteristics and serum levels of DLL4 in healthy controls and in patients with T2DM who had different severities of DR.

\section{Methods}

\section{Subjects}

From March 2019 to June 2019, 94 patients from the First Affiliated Hospital of Soochow University (Suzhou, China) were enrolled, all of whom were diagnosed with T2DM based on the 1999 WHO diagnostic criteria. According to the 2003 International Clinical Diabetic Retinopathy and Diabetic Macular Edema Severity Scales [9, 10], the patients were divided into 3 subgroups according to the clinical results (dilatation and fundus photography or fundus fluorescein angiography). There were 35 patients with no diabetic retinopathy (NDR), 32 patients with non-proliferative retinopathy (NPDR, with mild fundus lesions), and 27 patients with proliferative diabetic retinopathy (PDR, with neovascularization). An additional 30 healthy subjects without DM were selected from the physical examination center of the same institution as normal controls (NCs).

The main inclusion criteria were: diagnosis of diabetes for a certain course; microaneurysms, exudation, blood leakage in the fundus. For non-proliferative stage, retinal dot and blot hemorrhage and hard exudation or cotton wool spots are the clinical manifestations. For proliferative stage, neovascularization occurs in the retina, which seriously affects vision and life quality. The main exclusion criteria were: severe complications of DM; type 1 $\mathrm{DM}$, gestational diabetes, or any other type of DM; severe functional impairment or disorder of the liver or kidneys; acute and/or chronic infection, such as intestinal infection, urinary tract infection, and respiratory tract infection; recent trauma, surgery, or complication from a cardiovascular or cerebrovascular event or other stress; autoimmune disease; another fundus disease, such as macular degeneration; and chronic smoking or drinking of alcohol. All subjects provided informed consent. This study was approved by the ethics committee of the First Affiliated Hospital of Soochow University (2019059), and all methods were performed in accordance with the relevant guidelines and regulations.

\section{General and laboratory data}

Age, sex, duration of DM, body mass index (BMI), diastolic blood pressure (DBP), systolic blood pressure (SBP), and other general information were recorded. Fasting venous blood was obtained before treatment, and serum and plasma were separated by centrifugation. The serum concentration of DLL4 was detected using an ELISA according to the manufacturer's instructions (Blue Gene). A Hitachi7600 automatic analyzer was used to measure the level of fasting blood glucose (FBG) by the glucose oxidase method; and the levels of total cholesterol (TC), triglycerides (TG), high-density lipoprotein cholesterol (HDL-C), and low-density lipoprotein cholesterol (LDL-C) by an enzymatic method. The

Table 1 Baseline clinical characteristics of participants in the four groups

\begin{tabular}{|c|c|c|c|c|}
\hline Index & NC & NDR & NPDR & PDR \\
\hline Number & 30 & 35 & 32 & 27 \\
\hline Age (years) & $53.0 \pm 10.6$ & $55.9 \pm 12.8$ & $53.9 \pm 9.4$ & $56.0 \pm 13.6$ \\
\hline Sex (Male/female) & $16 / 14$ & $19 / 16$ & $18 / 14$ & $12 / 15$ \\
\hline Duration of diabetes (years) & - & $6.54 \pm 5.01$ & $10.87 \pm 6.17^{b}$ & $16.33 \pm 8.02^{\mathrm{bc}}$ \\
\hline $\mathrm{BMI}\left(\mathrm{kg} / \mathrm{m}^{2}\right)$ & $22.70 \pm 1.85$ & $24.31 \pm 3.72^{\mathrm{a}}$ & $25.09 \pm 3.10^{\mathrm{a}}$ & $25.07 \pm 2.88^{\mathrm{a}}$ \\
\hline $\mathrm{SBP}(\mathrm{mmHg})$ & $122.27 \pm 18.41$ & $131.66 \pm 15.35^{\mathrm{a}}$ & $138.12 \pm 20.03^{\mathrm{a}}$ & $144.73 \pm 18.50^{\mathrm{ab}}$ \\
\hline $\mathrm{DBP}(\mathrm{mmHg})$ & $73.6 \pm 12.83$ & $82.48 \pm 11.47^{\mathrm{a}}$ & $88.59 \pm 13.48^{\mathrm{a}}$ & $88.31 \pm 1.50^{\mathrm{a}}$ \\
\hline
\end{tabular}

${ }^{a}$ : Significantly different from $\mathrm{NC}^{\mathrm{b}}$ : Significantly different from $\mathrm{NDR}^{\circ}{ }^{\mathrm{c}}$ : Significantly different from NPDR 
Table $\mathbf{2}$ Laboratory data of participants in the four groups

\begin{tabular}{lllll}
\hline Index & NC & NDR & NPDR & PDR \\
\hline HbA1C (\%) & $5.31 \pm 0.22$ & $7.96 \pm 1.37^{\mathrm{a}}$ & $9.34 \pm 1.78^{\mathrm{ab}}$ & $10.48 \pm 1.99^{\mathrm{abc}}$ \\
TC $(\mathrm{mmol} / \mathrm{L})$ & $3.99 \pm 0.47$ & $4.57 \pm 1.02^{\mathrm{a}}$ & $4.74 \pm 1.31^{\mathrm{a}}$ & $4.94 \pm 1.50^{\mathrm{a}}$ \\
TG (mmo//L) & $1.09 \pm 0.30$ & $1.51 \pm 0.98^{\mathrm{a}}$ & $2.15 \pm 1.10^{\mathrm{ab}}$ & $3.50 \pm 2.76^{\mathrm{abc}}$ \\
$\mathrm{HDL}-\mathrm{C}(\mathrm{mmol} / \mathrm{L})$ & $1.34 \pm 0.31$ & $1.12 \pm 0.28^{\mathrm{a}}$ & $1.01 \pm 0.27^{\mathrm{a}}$ & $0.98 \pm 0.45^{\mathrm{a}}$ \\
LDL-C (mmol/L) & $2.23 \pm 0.38$ & $2.76 \pm 0.89^{\mathrm{a}}$ & $2.93 \pm 1.09^{\mathrm{a}}$ & $3.02 \pm 0.99^{\mathrm{a}}$ \\
FBG (mmol/L) & $5.20 \pm 0.34$ & $8.22 \pm 3.3^{\mathrm{a}}$ & $8.85 \pm 2.27^{\mathrm{a}}$ & $10.02 \pm 1.75^{\mathrm{abc}}$ \\
Urine protein/creatinine & - & $0.11 \pm 0.11$ & $0.34 \pm 0.39^{\mathrm{b}}$ & $1.51 \pm 0.87^{\mathrm{bc}}$ \\
DLL4 (pg/mL) & $29.9 \pm 8.92$ & $43.38 \pm 16.23^{\mathrm{a}}$ & $56.57 \pm 25.89^{\mathrm{ab}}$ & $74.97 \pm 25.28^{\mathrm{abc}}$ \\
\hline
\end{tabular}

${ }^{a}$ : Significantly different from NC; ${ }^{\text {b }}$ : Significantly different from NDR; ${ }^{c}$ : Significantly different from NPDR

concentration of glycated hemoglobin (HbA1c) was determined by high pressure liquid chromatography using the Bio-Rad Variant II glycosylated hemoglobin detector. Morning urine was collected in a disposable container without contamination. Urinary protein was measured using an automatic analyzer, and the protein-creatinine ratio was calculated for assessment of proteinuria.

\section{Statistical analysis}

All data were recorded and collated using Microsoft Excel, and statistical analyses were performed using SPSS version 23.0. Count data were presented as numbers and compared using the chi-square test, and continuous data were presented as means and standard deviations. Analysis of variance was used to compare the different groups. The relationships of DLL4 with other clinical indicators were determined using Pearson correlation analysis. A logistic regression model was used to identify factors associated with DR. A receiver operating characteristic (ROC) curve was used to determine the

Table 3 Correlation of DLL4 with other clinical indicators in T2DM participants

\begin{tabular}{lll}
\hline Index & $\boldsymbol{r}$ & $\boldsymbol{p}$ \\
\hline Sex & -0.019 & 0.835 \\
Age & -0.036 & 0.695 \\
HDL-C & -0.193 & $\mathbf{0 . 0 3 2}$ \\
Duration of diabetes & 0.191 & 0.066 \\
DBP & 0.161 & 0.075 \\
LDL-C & 0.098 & 0.279 \\
BMl & 0.177 & $\mathbf{0 . 0 4 9}$ \\
SBP & 0.218 & $\mathbf{0 . 0 1 6}$ \\
HbA1C & 0.529 & $\mathbf{0}$ \\
FBG & 0.492 & $\mathbf{0}$ \\
TC & 0.209 & $\mathbf{0 . 0 2}$ \\
TG & 0.323 & $\mathbf{0}$ \\
Urine protein/creatinine & 0.177 & $\mathbf{0 . 0 1 5}$ \\
\hline
\end{tabular}

optimal cut-off value of DLL4 for the diagnosis if DR. A $\mathrm{P}$-value below 0.05 was considered significant.

\section{Results}

General characteristics of the four groups

The four groups had no significant differences in gender or age (all $p>0.05$; Table 1 ). The PDR group had a longer duration of T2DM than the NPDR group, and both groups had longer durations of T2DM than the NDR group (all $p<$ $0.05)$. All T2DM groups together had a significantly greater $\mathrm{BMI}$ than the NC group $(p<0.05)$, but the $3 \mathrm{~T} 2 \mathrm{DM}$ groups had no significant differences in BMI. Analysis of SBP indicated that all T2DM groups together had a greater level than the NC group $(p<0.05)$; the differences between the NDR and NPDR groups and between the NPDR and PDR groups were not statistically significant; but the NDR group had a significantly lower level than the PDR group $(p<0.05)$. All T2DM groups together had a greater DBP than the NC group $(p<0.05)$, but the 3 T2DM groups had no significant differences in DBP.

\section{Biochemical indexes of the four groups}

All T2DM groups together had greater levels of HbA1c, TC, TG, LDL-C, and FBG and a lower level of HDL-C than the NC group (all $p<0.05$; Table 2). The NPDR and PDR groups had greater levels of HbAlc, TG, and urinary protein/creatinine ratio than the NDR group, and the PDR group had greater levels of HbA1c, TG, and urinary protein/creatinine ratio than the NPDR group (all $p<0.05$ ). The PDR group had a greater FBG than the NDR and NPDR groups (all $p<0.05$ ). However, the NDR and NPDR groups had no significant difference in FBG, and the three T2DM groups had no significant differences in TC, HDL-C, and LDL-C.

The NDR, NPDR, and PDR groups each had a higher DLL4 level than the NC group (all $p<0.01$ ). In addition, the NPDR group had a higher DLL4 level than the NDR group $(p<0.05)$, and the PDR group had a higher DLL4 level than the NDR group and the NPDR group (both $p<0.01)$. 


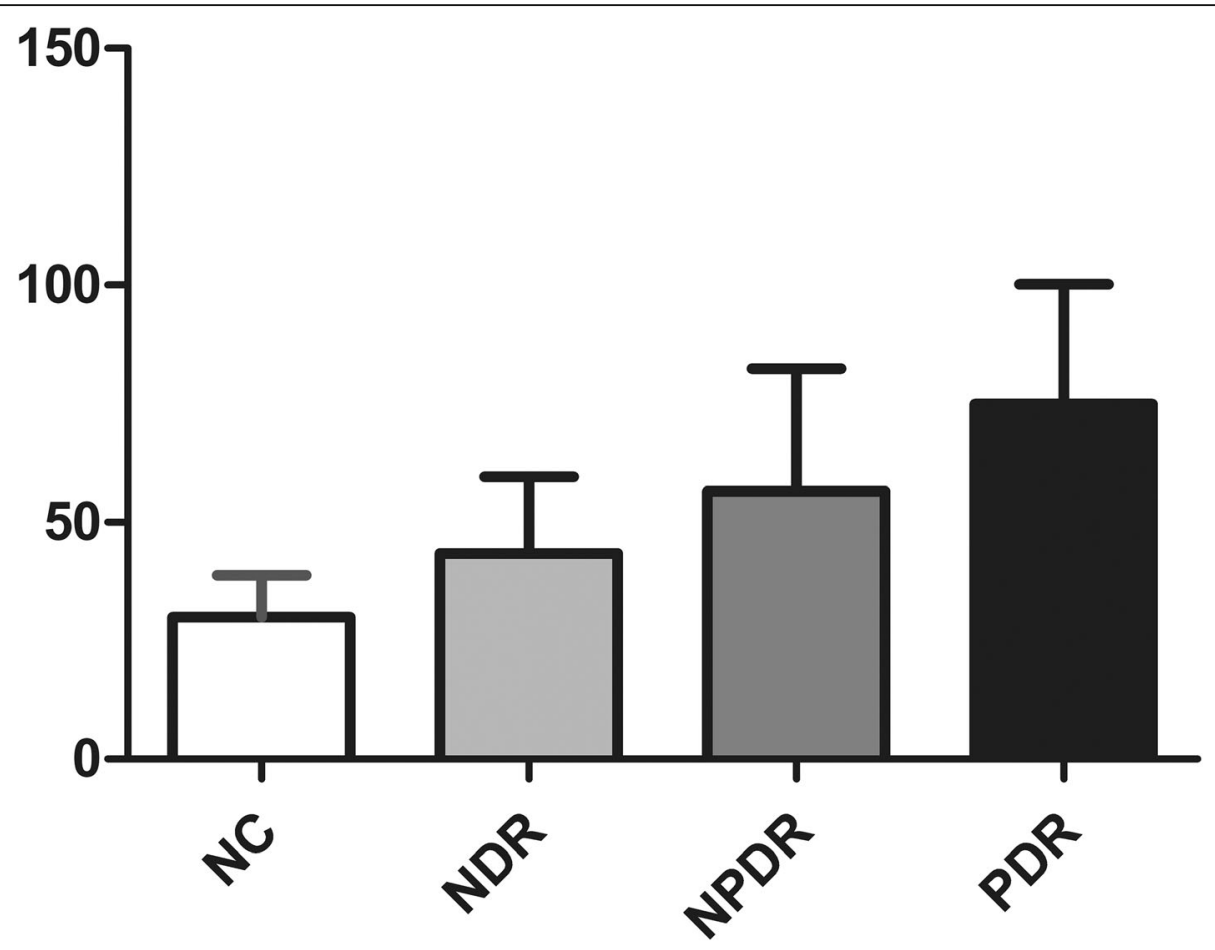

Fig. 1 Serum concentration of DLL4 in each group. a: significantly different from the NC group; b: significantly different from the NDR group; c: significantly different from the NPDR group

\section{Correlation of DLL4 with other clinical indicators}

Pearson correlation analysis of all NC and T2DM participants indicated that the DLL4 level was positively associated correlated with BMI, SBP, HbA1c, FBG, TC, TG, and the ratio of urinary protein and creatinine, and negatively associated with HDL-C (all $p<0.05$; Table 3; Fig. 1).

\section{Use of DLL4 for identification of DR}

We then examined the effect of the of duration of diabetes, SBP, HbA1c, and DLL4 (independent variables) on DR (dependent variable). Multivariate logistic regression analysis indicated that each of these independent variables was an were independent risk factor for T2DM with DR (all $p<0.05$; Table 4 ), and DDL4 was also an independent risk factor for T2DM with PDR (Supplementary Table 1). Notably, the level of DLL4 was greater in patients than in healthy controls.

To evaluate the possible use of DLL4 for the diagnosis of DR in clinical settings, we also performed receiver operating characteristic (ROC) analysis (Fig. 2). The results indicated excellent diagnostic performance, with an area

Table 4 Multivariate logistic regression analysis of factors associated with diabetic retinopathy

\begin{tabular}{|c|c|c|c|c|c|c|}
\hline \multirow[b]{2}{*}{ Variate } & \multicolumn{3}{|c|}{ unadjusted } & \multicolumn{3}{|c|}{ adjusted } \\
\hline & $p$ & OR & $95 \% \mathrm{Cl}$ & $p$ & OR & $95 \% \mathrm{Cl}$ \\
\hline DLL4 & 0.000 & 1.046 & $1.020,1.073$ & 0.008 & 1.108 & $1.027,1.195$ \\
\hline Duration of T2DM & 0.000 & 1.179 & $1.083,1.282$ & 0.007 & 1.804 & $1.178,2.764$ \\
\hline FBG & 0.000 & 1.502 & $1.214,1.859$ & 0.013 & 1.583 & $1.108,2.263$ \\
\hline $\mathrm{HbA1c}$ & 0.000 & 1.973 & $1.412,2.756$ & 0.025 & 1.793 & $1.091,3.246$ \\
\hline $\mathrm{BMI}$ & 0.536 & 0.722 & $0.257,2.026$ & 0.118 & 0.788 & $0.584,1.062$ \\
\hline SBP & 0.525 & 1.022 & $0.956,1.092$ & 0.224 & 1.029 & $0.983,1.076$ \\
\hline $\mathrm{TC}$ & 0.055 & 0.028 & $0.001,1.082$ & 0.068 & 0.5 & $0.002,1.243$ \\
\hline $\mathrm{TG}$ & 0.230 & 0.730 & $0.331,1.278$ & 0.072 & 3.838 & $0.889,3.017$ \\
\hline LDL-C & 0.125 & 5.572 & $0.437,1.562$ & 0.088 & 4.272 & $0.676,1.236$ \\
\hline $\mathrm{HDL}-\mathrm{C}$ & 0.249 & 1.710 & $0.053,9.633$ & 0.96 & 0.909 & $0.022,7.121$ \\
\hline Urine protein/creatinine & 0.073 & 1.710 & $0.546,4.606$ & 0.057 & 1.116 & $0.810,3.627$ \\
\hline
\end{tabular}




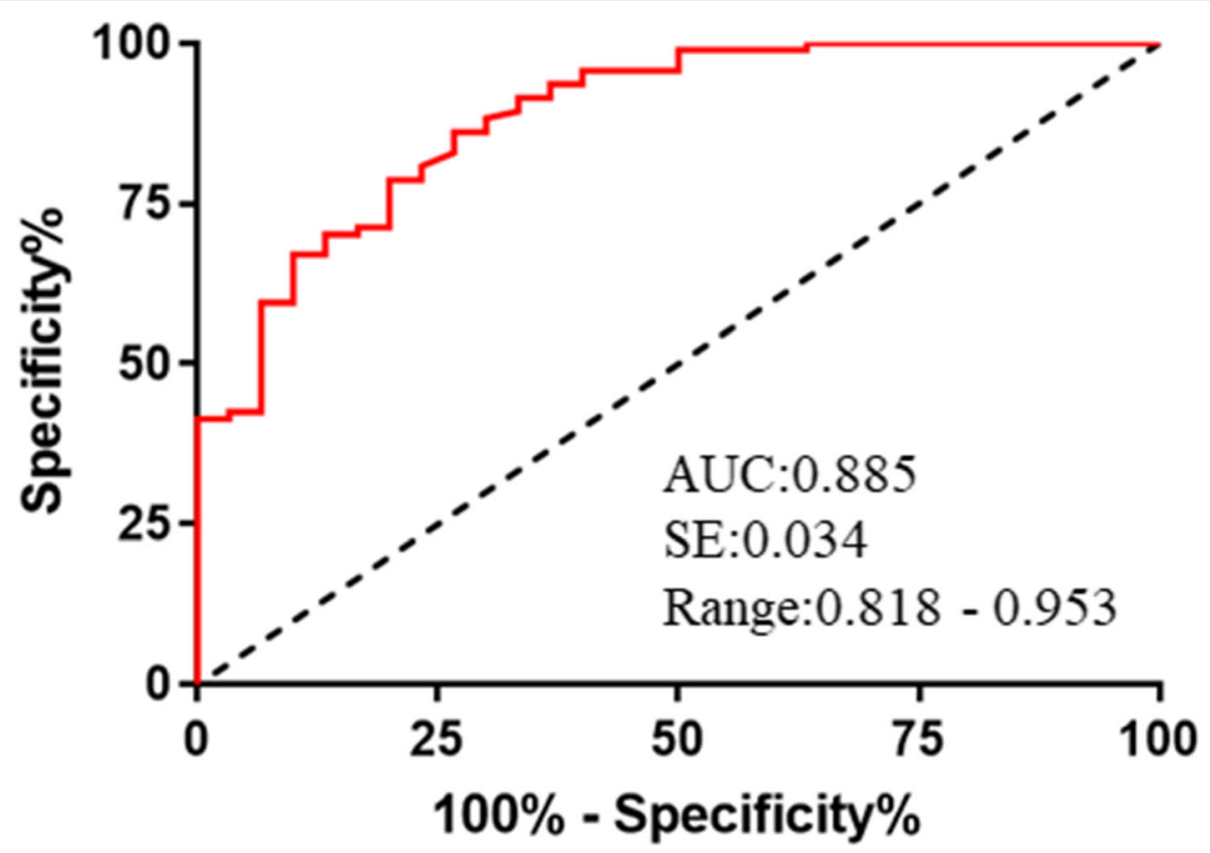

Fig. 2 Use of serum DLL4 level for diagnosis of DR (ROC curve analysis). Patients in the NDR group were compared with those in the NPDR and PDR groups

under the curve (AUC) of 0.885 (SE: 0.034; range: $0.818-0.953)$.

\section{Discussion}

The pathogenesis of DR is complex and is related to alterations in multiple pathways and molecules. These alterations include the formation of glycosylated end products, oxidative stress, up-regulation of matrix metalloproteinase, production of multiple growth factors, and secretion of adhesion molecules, although the specific mechanism is still not fully understood [1, 11]. The formation of new blood vessels during the pathological process of PDR is generally believed to be related to the production of retinal angiogenic factors caused by localized ischemia and hypoxia [12]. The most important marker of PDR is fundus neovascularization, defined by the formation of a large number of fibrous vascular membranes, and this can lead to vitreous hemorrhage and the occurrence of late traction retinal detachment [13]. Thus, fundus lesion with neovascularization caused by hypoxia is the most clinically significant alteration in DR.

Patients with PDR have impaired retinal microvascular cells, and this leads to retinal microvascular occlusion and the formation of non-perfusion areas, followed by ischemia and hypoxia in local tissues. There is evidence that hypoxia is an important initiator of the notch signaling pathway in DR [14]. Recent studies identified biomarkers and risk associated with retinal disorders in patients with DM, including C1q/TNF-related protein (CTRP3), lipasin, and microRNA-211, and these molecules may be novel therapeutic targets for the prevention or treatment of DR [15-18]. Our study showed that an elevated serum DLL4 level was an independent risk factor for DR. Other studies of the development of neovascularization in PDR patients reported that the DLL4/ notch1 signaling pathway acted on the endothelium to regulate vascular remodeling, reduced the number of vascular buds and collaterals, and promoted the differentiation and maturation of neovascularization $[14,19,20]$. DR is a progressive complication of DM, and long-term hyperglycemia is the main cause of the onset and progression of DR. More specifically, a long-term high level of blood glucose and abnormal hemodynamics lead to retinal blood vessel deformation, endothelial cell damage, and damage of the blood-retinal barrier, and these all increase retinal vascular permeability and retinal leakage as the disease progresses. Notably, these pathological changes are sustained by a high level of blood glucose $[21,22]$. As a result, severe vitreous hemorrhage and retinal detachment may occur. These previous findings are consistent with our current findings that FBG, HbA1c, and duration of T2DM were independent risk factors for DR.

DR fundus lesions are characterized by increased vascular permeability, formation of soft tissue ischemia, leakage from new blood vessels, bleeding, and other alterations. A prolonged high level of blood glucose can cause microvascular abnormalities, and patients with 
DM are often characterized by dyslipidaemia and clumping of blood cells, and thus leading to microcirculation disturbances and propel DR forward [14]. All of these pathological changes can contribute to an increased level of DLL4. Our study suggests that DLL4 plays a role in the onset and progression of DR, and can serve as a potential biomarker for assessing the risk and severity of DR. However, there are some limitations in the present study. Firstly, the level of DLL4 is also increased in many other diseases, such as infections by various pathogens, cardiovascular disease, kidney disease, tumors, and vasculitis [23-25]. Secondly, animal studies indicated that inhibition of DLL4 contributed to angiogenesis, which is quite contrary to our findings in patients with T2DM [8, $26,27]$. Thus, the usefulness of DLL4 as a specific biomarker of DR in clinical settings needs to be confirmed by further studies with large sample sizes. Thirdly, we did not check the relationship between the level of DLL4 and diabetic macular edema.

\section{Abbreviations}

DR: Diabetic retinopathy.; NDR: No diabetic retinopathy.; NDPR: Nonproliferative diabetic retinopathy.; PDR: Proliferative diabetic retinopathy.; T2DM: Type 2 diabetes mellitus.; DLL4: Delta-like ligand-4.;

HbA1c: Glycosylated hemoglobin.; FBG: Fasting blood glucose.; ROC: Receiver operating characteristic.; IDF: International Diabetes Federation.; BMI: Body mass index.; DBP: Diastolic blood pressure.; SBP: Systolic blood pressure.; TC: Total cholesterol.; TG: Triglyceride.; HDL-C: High-density lipoprotein cholesterol.; LDL-C: Low-density lipoprotein cholesterol.

\section{Supplementary Information}

The online version contains supplementary material available at https://doi. org/10.1186/s12902-021-00814-6.

Additional file 1:

\section{Acknowledgements}

Not applicable.

\section{Authors' contributions}

Design: YYZ, KC; Clinical data collection: YZ, JH; Data entry: QF; Data analysis: $Y Y Z, X D$. All authors read and approved the final manuscript.

\section{Funding}

Not applicable.

\section{Availability of data and materials}

The datasets used and/or analyzed during the current study are available from the corresponding author on reasonable request.

\section{Declarations}

\section{Ethics approval and consent to participate}

This study was approved by the ethics committee of the First Affiliated Hospital of Soochow University (2019-059), and all methods were carried out in accordance with relevant guidelines and regulations. All subjects provided the written informed consent to participate.

\section{Consent for publication}

Not applicable.

\section{Competing interests}

The authors declare that they have no competing interests.

\section{Author details}

${ }^{1}$ Department of Endocrinology, The First Affiliated Hospital of Soochow University, No.188 Shizi Road, Suzhou, China. ${ }^{2}$ Department of Thoracic Surgery, The First Affiliated Hospital of Soochow University, No.188 Shizi Road, Suzhou, China.

Received: 22 March 2021 Accepted: 21 July 2021

Published online: 06 August 2021

\section{References}

1. Cheung N, Mitchell P, Wong TY. Diabetic retinopathy. Lancet. 2010; 376(9735):124-36. https://doi.org/10.1016/s0140-6736(09)62124-3.

2. Liang WJ, Yang HW, Liu HN, Qian W, Chen XL. HMGB1 upregulates NF-kB by inhibiting IKB-a and associates with diabetic retinopathy. Life Sci. 2020; 241117146. https://doi.org/10.1016/j.lfs.2019.117146.

3. IDF Congress 2017 - Shaping the future of diabetes. Diabetes Res Clin Pract. 2017;126317-9. https://doi.org/10.1016/j.diabres.2017.03.005

4. Antoszyk AN, Glassman AR, Beaulieu WT, Jampol LM, Jhaveri CD, Punjabi OS, et al. Effect of Intravitreous Aflibercept vs Vitrectomy With Panretinal Photocoagulation on Visual Acuity in Patients With Vitreous Hemorrhage From Proliferative Diabetic Retinopathy: A Randomized Clinical Trial. Jama. 2020;324(23):2383-95. https://doi.org/10.1001/jama.2020.23027.

5. Shan $Y, X u Y$, Lin $X$, Lou L, Wang Y, Ye J. Burden of vision loss due to diabetic retinopathy in China from 1990 to 2017: findings from the global burden of disease study. Acta Ophthalmol. 2020. https://doi.org/10.1111/a os.14573.

6. Barber AJ. Diabetic retinopathy: recent advances towards understanding neurodegeneration and vision loss. Sci China Life Sci. 2015;58(6):541-9. https://doi.org/10.1007/s11427-015-4856-x.

7. Shutter JR, Scully S, Fan W, Richards WG, Kitajewski J, Deblandre GA, et al. Dll4, a novel Notch ligand expressed in arterial endothelium. Genes Dev. 2000;14(11):1313-8.

8. Pedrosa AR, Trindade A, Fernandes AC, Carvalho C, Gigante J, Tavares AT, et al. Endothelial Jagged1 antagonizes D\|l4 regulation of endothelial branching and promotes vascular maturation downstream of Dll4/Notch1. Arterioscler Thromb Vasc Biol. 2015;35(5):1134-46. https://doi.org/10.1161/a tvbaha.114.304741.

9. Wilkinson CP, Ferris FL, 3rd, Klein RE, Lee PP, Agardh CD, Davis M, et al. Proposed international clinical diabetic retinopathy and diabetic macular edema disease severity scales. Ophthalmology. 2003;110(9):1677-82. https:// doi.org/10.1016/s0161-6420(03)00475-5.

10. Tatti P, Arrigoni F, Longobardi A, Costanza F, Di Blasi P, Merante D. Retrospective analysis of rosiglitazone and macular oedema in patients with type 2 diabetes mellitus. Clin Drug Investig. 2008;28(5):327-32. https://doi. org/10.2165/00044011-200828050-00006.

11. Moreno A, Lozano M, Salinas P. Diabetic retinopathy. Nutr Hosp. 2013;28 Suppl 253-6. https://doi.org/10.3305/nh.2013.28.sup2.6714.

12. Lobov IB, Renard RA, Papadopoulos N, Gale NW, Thurston G, Yancopoulos GD, et al. Delta-like ligand 4 (D\|l4) is induced by VEGF as a negative regulator of angiogenic sprouting. Proc Natl Acad Sci U S A. 2007;104(9): 3219-24. https://doi.org/10.1073/pnas.0611206104.

13. Safi H, Safi S, Hafezi-Moghadam A, Ahmadieh H. Early detection of diabetic retinopathy. Surv Ophthalmol. 2018;63(5):601-8. https://doi.org/10.1016/j. survophthal.2018.04.003.

14. Miloudi K, Oubaha M, Ménard C, Dejda A, Guber V, Cagnone G, et al. NOTCH1 signaling induces pathological vascular permeability in diabetic retinopathy. Proc Natl Acad Sci U S A. 2019;116(10):4538-47. https://doi. org/10.1073/pnas.1814711116.

15. Yan Z, Zhao J, Gan L, Zhang Y, Guo R, Cao X, et al. CTRP3 is a novel biomarker for diabetic retinopathy and inhibits HGHL-induced VCAM-1 expression in an AMPK-dependent manner. PLoS One. 2017;12(6):e0178253. https://doi.org/10.1371/journal.pone.0178253.

16. Liu HN, Cao NJ, Li X, Qian W, Chen XL. Serum microRNA-211 as a biomarker for diabetic retinopathy via modulating Sirtuin 1. Biochem Biophys Res Commun. 2018;505(4):1236-43. https://doi.org/10.1016/j.bbrc.2018.10.052.

17. Fang C, Huang Y, Guo H, Gao Y, Ji X, Hu J. Lipasin, a biomarker of diabetic retinopathy. Diabetes Res Clin Pract. 2016;11596-8. https://doi.org/10.1016/j. diabres.2016.01.029.

18. Jenkins AJ, Joglekar MV, Hardikar AA, Keech AC, O’Neal DN, Januszewski AS. Biomarkers in Diabetic Retinopathy. Rev Diabet Stud. 2015;12(1-2):159-95. https://doi.org/10.1900/rds.2015.12.159. 
19. Wimmer RA, Leopoldi A, Aichinger M, Wick N, Hantusch B, Novatchkova M, et al. Human blood vessel organoids as a model of diabetic vasculopathy. Nature. 2019;565(7740):505-10. https://doi.org/10.1038/s41586-018-0858-8.

20. Qin X, Zhang Z, Xu H, Wu Y. Notch signaling protects retina from nuclear factor-KB- and poly-ADP-ribose-polymerase-mediated apoptosis under highglucose stimulation. Acta Biochim Biophys Sin (Shanghai). 2011;43(9):70311. https://doi.org/10.1093/abbs/gmr069.

21. Zhang Y, Niu M, Li Y, Wang J, Qu B, Zheng CX, et al. [Prevalence and risk factors of diabetic retinopathy in hospital patients]. Zhonghua Yi Xue Za Zhi. 2018;98(6):440-4. https://doi.org/10.3760/cma.j.issn.0376-2491.2018.06. 009.

22. Ting DS, Tan KA, Phua V, Tan GS, Wong CW, Wong TY. Biomarkers of Diabetic Retinopathy. Curr Diab Rep. 2016;16(12):125. https://doi.org/10.1 007/s11892-016-0812-9.

23. Pabois A, Pagie S, Gérard N, Laboisse C, Pattier S, Hulin P, et al. Notch signaling mediates crosstalk between endothelial cells and macrophages via DII4 and IL6 in cardiac microvascular inflammation. Biochem Pharmacol. 2016;10495-107. https://doi.org/10.1016/j.bcp.2016.01.016.

24. Wang $X$, Zhang J, Wang Y, Tu M, Wang Y, Shi G. Upregulated VEGFA and DLL4 act as potential prognostic genes for clear cell renal cell carcinoma. Onco Targets Ther. 2018;111697-706. https://doi.org/10.2147/ott.S150565.

25. Hu GH, Liu H, Lai P, Guo ZF, Xu L, Yao XD, et al. Delta-like ligand 4 (D\|4) predicts the prognosis of clear cell renal cell carcinoma, and anti-DII4 suppresses tumor growth in vivo. Int J Clin Exp Pathol. 2014;7(5):2143-52.

26. Yang JM, Ryu J, Kim I, Chang H, Kim IK. DII4 Blockade Promotes Angiogenesis in Nonhealing Wounds of Sox7-Deficient Mice. Adv Wound Care (New Rochelle). 2020;9(11):591-601. https://doi.org/10.1089/wound.201 9.1015.

27. Yoon CH, Choi YE, Cha YR, Koh SJ, Choi Jl, Kim TW, et al. Diabetes-Induced Jagged1 Overexpression in Endothelial Cells Causes Retinal Capillary Regression in a Murine Model of Diabetes Mellitus: Insights Into Diabetic Retinopathy. Circulation. 2016;134(3):233-47. https://doi.org/10.1161/circula tionaha.116.014411.

\section{Publisher's Note}

Springer Nature remains neutral with regard to jurisdictional claims in published maps and institutional affiliations.

Ready to submit your research? Choose BMC and benefit from:

- fast, convenient online submission

- thorough peer review by experienced researchers in your field

- rapid publication on acceptance

- support for research data, including large and complex data types

- gold Open Access which fosters wider collaboration and increased citations

- maximum visibility for your research: over $100 \mathrm{M}$ website views per year

At BMC, research is always in progress.

Learn more biomedcentral.com/submissions 